\title{
Retention efficiency of sub-micrometer particles by the pharyngeal filter of the pelagic tunicate Oikopleura vanhoeffeni
}

\author{
Don Deibel, S. H. Lee \\ Marine Sciences Research Laboratory, Ocean Sciences Centre, and Department of Biology, Memorial University \\ of Newioundland, St. John's, Newfoundland A1C 5S7, Canada
}

\begin{abstract}
Retention efficiencies of 0.6 to $7 \mu \mathrm{m}$ diameter particles were determined for the pelagic tunicate Oikopleura vanhoeffeni by offering individuals a graded series of latex microspheres and measuring the change in volume proportion directly by microscope counts of the number of beads of each size in suspension vs in the gut. Beads the size of free-living bacteria $(0.6 \mu \mathrm{m})$ were retained with a mean efficiency of $44 \pm 8 \%( \pm 95 \% \mathrm{Cl})$, whereas 1,3 and $7 \mu \mathrm{m}$ beads were retained with mean efficiencies of $58 \pm 8 \%, 88 \pm 6 \%$ and $91 \pm 3 \%$, respectively. These results support our earlier ultrastructural predictions of a coarse pharyngeal filter mesh, and show that the food concentrating filter does not alone determine the size composition of the ingested ration. Retention of sub-micrometer particles (0.6 and $1 \mu \mathrm{m}$ beads) was dependent on body size, with mean values of $<20 \%$ for specimens longer than $3 \mathrm{~mm}$. These retention spectra are similar to those of salps and ascidians, but show that appendicularians retain sub-micrometer particles more efficiently than do salps. We conclude that $O$. vanhoeffeni is capable of mediating a shunt of microbial biomass directly from bacteria, other picoplankton and small nanoflagellates to large metazoans, including known fish predators of appendicularians
\end{abstract}

\section{INTRODUCTION}

Energy flow through microbial communities is significant in the sea, raising the question of how and to what extent microbial food webs are linked to metazoans. It is widely believed that microbial webs contain many predator-prey linkages, and thus are sinks for organic matter within which much energy is spent by various sizes and types of bacteria and Protozoa in respiratory maintenance (Ducklow 1983).

Pelagic tunicates feed by pumping water through fibrous mucous filters with very fine rectangular pores (Alldredge \& Madin 1982), and are considered to be non-selective grazers, collecting particles by sieving (Randlov \& Riisgård 1979, Jørgensen 1983). Flood (1978) suggested that appendicularian tunicates should retain free-living bacteria efficiently, because of the extremely small pores of the external, food-concentrating filter within the mucous 'house' in which they live (i.e. $0.24 \times 0.07 \mu \mathrm{m}$ for Oikopleura dioica). If pelagic tuni- cates consume free-living bacteria and small flagellates efficiently, then microbial biomass may be transferred directly from very small size-classes to much larger ones, including those fish that prey on tunicates (Alldredge \& Madin 1982, Keats et al. 1987). In addition, if microbes are digested during gut passage, bacteria and other picoplankton may serve as a source of energy or essential nutrients for appendicularians.

This study was designed to determine the sizeretention efficiency of individual Oikopleura vanhoeffeni. It is the first such investigation for any appendicularian, and the first attempt to compare filter ultrastructure (Deibel et al. 1985, Deibel \& Powell 1987 a) to empirically-determined retention efficiencies for any pelagic tunicate. The few published studies of other tunicates have shown that both salps (Harbison \& McAlister 1979, Mullin 1983. Caron et al. 1989) and ascidians (Randløv \& Riisgård 1979, Jørgensen et al. 1984) are capable of retaining particles as small as $3 \mu \mathrm{m}$ with $100 \%$ efficiency. 


\section{METHODS}

Retention efficiency was determined by offering individual Oikopleura vanhoeffeni a graded series of monodispersed, fluorescent, non-carboxylated, latex microspheres 0.6, 1.0, 3.1 and 7.0 $\mu \mathrm{m}$ in diameter (Polysciences Corp., Warrington, PA, USA). From February to May 1987, SCUBA divers used $450 \mathrm{ml}$ glass jars to capture individual appendicularians (1 specimen per jar) along with naturally occurring particulate matter in Logy Bay, insular Newfoundland, Canada. Specimens were maintained in these jars for several hours in the laboratory at in situ temperatures of -0.7 to $9.2^{\circ} \mathrm{C}$. Later the same day, a mixture of latex beads was added to the jars with each size offered in equal concentration by volume, either in pairs $(n=36)$, in groups of 3 sizes $(n=6)$ or all 4 sizes together $(n=30$; Table 1$)$. For reference, the $7 \mu \mathrm{m}$ beads were offered in all experiments. There was no difference in the retention efficiency of any of the bead sizes when offered in pairs or in groups of 3 vs when they were all offered together (based on visual inspection of scatter plots of retention efficiency vs trunk length, and pairwise $t$-tests of the mean efficiencies; $p>0.20)$. Thus, all data were pooled for each bead size before analysis.

The feeding mechanism of appendicularians is complex, with external pre-filters and food-concentrating filters in the house, and an internal pharyngeal filter within the animal (Deibel 1986, Flood 1991). The external filters are secreted by the animal and are subject to clogging, leading eventually to the animal abandoning its house. To minimize clogging and abandonment during experiments, it is important to maintain the concentration of tracer particles as low as possible. Thus, we selected a nominal concentration of $0.6 \mu \mathrm{m}$ beads of $1 \times 10^{5} \mathrm{ml}^{-1}$ (or $1 \times 10^{4} \mu^{3} \mathrm{ml}^{-1}$ ), equivalent to the concentration of free-living bacteria in Newfoundland coastal waters (Pomeroy \& Deibel 1986, Pomeroy et al. 1991). The nominal concentration of 1,3 and $7 \mu \mathrm{m}$ beads was $10^{4}, 10^{3}$ and $60 \mathrm{ml}^{-1}$, respectively.

Table 1. The number of experiments ( $\mathrm{n}$ ) in which different combinations of bead sizes were offered to Oikopleura vanhoeffeni. Note that the $7 \mu \mathrm{m}$ beads were offered in all experiments

\begin{tabular}{|lr|}
\hline $\begin{array}{l}\text { Bead mixture } \\
\text { (diameter in } \mu \mathrm{m} \text { ) }\end{array}$ & $\mathrm{n}$ \\
\hline $0.6+1+3+7$ & 30 \\
$0.6+3+7$ & 2 \\
$1+3+7$ & 4 \\
$0.6-7$ & 23 \\
$1+7$ & 5 \\
$3+7$ & 8 \\
Total ' $n$ ' & 72 \\
\hline
\end{tabular}

The observed volume concentration of each size over all experiments was within $11 \%$ of these nominal target concentrations, and the mean volume concentration of all bead sizes relative to that of the $7 \mu \mathrm{m}$ beads did not differ from unity (compare the open bars in Fig. 1).

To ensure that the beads did not aggregate, solutions were freshly prepared in $100 \mathrm{ml}$ of filtered seawater just before the experiments, 4 drops of anionic surfactant were added $10.4 \%$ final concentration of IsotergeR II, Coulter Electronics Corp.), and the suspensions were stirred in a vortex mixer and then sonicated. A few hundred $\mu \mathrm{l}$ up to 1 to $2 \mathrm{ml}$ of each bead suspension was added to each $450 \mathrm{ml}$ jar to begin the experiments, which lasted from 20 to $59 \mathrm{~min}$ depending on specimen size, ensuring that no beads were defecated. Because Oikopleura vanhoeffeni is large and sensitive to turbulence, specimens could not be transferred to filtered seawater for the experiments, nor could the jars be stirred. Trial counts of samples from unstirred jars without specimens showed no evidence of differential sedimentation of beads. Experiments were terminated by adding MS-222, followed by formaldehyde, to a final concentration of 2 to $4 \%$. Animal body size (i.e. trunk length) was measured with a dissecting microscope and ocular micrometer to the nearest $25 \mu \mathrm{m}$ ( $\bar{x}$ trunk length $\pm \mathrm{SD}=2.42 \pm 0.78 \mathrm{~mm}, \mathrm{n}=72$, range $=1.05$ to $4.35 \mathrm{~mm}$ ).

Next, triplicate 2-ml subsamples of the suspension were passed through 0.45 Millipore membrane filters (25 mm diameter) which were mounted under a cover glass with immersion oil, and the beads counted using a standard Zeiss epifluorescence microscope with acridine orange filter set \#487709 (BP450-490 exciter filter, FT510 chromatic beam-splitter and LP520 barrier filter). In addition, the gut of each animal (including fecal pellets when present) was removed and macerated in filtered seawater followed by sonication to disrupt tissue. These ingested beads were then filtered and counted as above for the suspension subsamples. The median coefficient of variation (CV) of triplicate counts of the beads in suspension for $0.6,1$ and $3 \mu \mathrm{m}$ beads ranged from 5 to $7 \%$, and that of the $7 \mu \mathrm{m}$ beads was $12 \%$. The median $\mathrm{CV}$ of replicate fields counted on the filters containing ingested beads ranged from 10 to $12 \%$ for all bead sizes. The number of fields counted on each slide varied depending on bead size, but whenever possible, sufficient fields were counted until at least 100 counts were registered for each bead size. The mean number of beads counted per filter for all bead sizes, both in suspension and ingested, was $>122$ (total number of slides counted for the entire study was ca 360). 
Retention efficiencies were estimated by first calculating the forage ratio $(F R)$, which is dependent on the proportion of beads of a given size ' $i$ ' in the gut vs in the feeding suspension (Jacobs 1974),

$$
F R,=\frac{V G_{i} / V G_{T o t}}{V S_{i} / V S_{\text {Tot }}}
$$

where VG and VS are the volume concentrations of bead size ' $i$ ' in the gut and suspension, respectively, and $V G_{\text {Tol }}$ and $V S_{\text {Tol }}$ are the summed volume concentrations of all bead sizes in the gut and suspension, respectively. The forage ratio ranges from 0 to 1 for negative selection, and from 1 to $\infty$ for positive selection. Retention efficiency of a given bead size was then calculated as,

$$
R E(\%)=F R_{1} / F R_{\mathrm{Max}} \times 100 \%
$$

where $F R_{\text {Max }}$ is the forage ratio for the bead size that is retained with highest efficiency (i.e. has the highest $F R$ ) for a given animal. The pairwise $t$-test was used for comparison of mean retention efficiencies of different bead sizes (or the Wilcoxon Signed Rank test where the mean, pairwise difference was not normally distributed). For comparison of the mean retention efficiencies of a particular bead size between different groups of animals, the $t$-test was used when there were 2 groups, and 1-way ANOVA was used when there were more than 2 groups (after arcsin transformation of the proportions when necessary to ensure normality). Using the forage ratio is appealing because it does not rely on recovering $100 \%$ of the ingested beads, as does the clearance-rate ratio approach (Harbison \& McAlister 1979).

\section{RESULTS}

Although all bead sizes were present in suspension in equal volume concentration (see open bars; Fig. 1), 0.6 and $1 \mu \mathrm{m}$ beads were not retained with $100 \%$ efficiency, being present in the ingested ration in mean proportions of $0.45 \pm 0.10$ and $0.69 \pm 0.12$, respectively (Fig. 1). The mean forage ratio increased with increasing bead diameter, showing strongest selection against $0.6 \mu \mathrm{m}$ beads and selection for $7 \mu \mathrm{m}$ beads (Table 2 ). Conversion to retention efficiencies showed that $0.6 \mu \mathrm{m}$ beads were retained with a mean efficiency ( $\pm 95 \% \mathrm{CI}$ ) of $44 \pm 8 \%$, significantly lower than the retention of $1 \mu \mathrm{m}$ beads $(58 \pm 8 \%, \mathrm{p}<0.001)$, which itself was significantly lower than the retention of $3 \mu \mathrm{m}$ beads $(88 \pm 6 \%, p<0.001)$. The mean retention efficiencies of 3 and $7 \mu \mathrm{m}$ beads were not significantly different $(p>0.80)$. There was residual variation in the

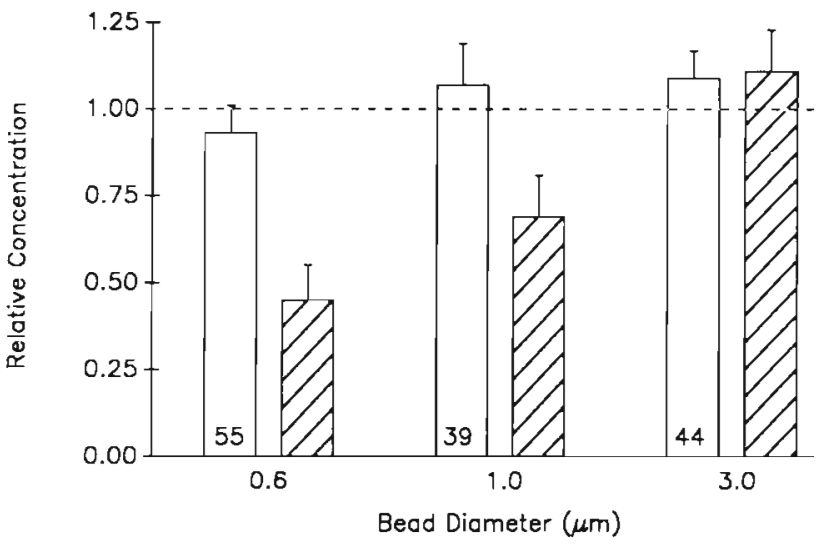

Fig. 1. Oikopleura vanhoeffeni. Frequency histogram of the mean volume concentration of $0.6,1$ and $3 \mu \mathrm{m}$ beads relative to that of $7 \mu \mathrm{m}$ beads in the feeding suspension (open bars) and in the gut (diagonally hatched bars). A relative volume concentration of 1.00 indicates that the concentration is equal to that of the $7 \mu \mathrm{m}$ beads. Number at bottom of open bars is $n$ for both open and diagonal bars. Error bar indicates upper $95 \%$ confidence interval of the mean

mean retention efficiency data that could not be ascribed to measurement error (see 'Methods') or particle size (see CIs in Table 2). Next we looked for other potential sources of variation.

The mean retention efficiency of $0.6 \mu \mathrm{m}$ beads was significantly lower for individuals $>3.0 \mathrm{~mm}$ long $(20 \pm 9 \%)$ in comparison to that of all smaller bodysize groups ( $F=4.46, \mathrm{p}<0.001$; Fig. 2$)$. The same trend was observed for $1.0 \mu \mathrm{m}$ beads, although the small number of observations in the largest body-size class ( $\mathrm{n}=3$ ) obviates statistical comparison. The mean retention efficiency of 3 and $7 \mu \mathrm{m}$ beads showed no similar decrease with increasing body size, ranging from 77 to $96 \%$ for all body-size classes (Fig. 2). Thus, for the largest individuals ( $>3 \mathrm{~mm}$ long), the retention index (i.e. the particle size retained with $50 \%$ efficiency; Harbison \& McAlister 1979) was between 1 and $3 \mu \mathrm{m}$.

To maintain equal volume concentration of all bead sizes in these experiments meant that the numerical abundance of $7 \mu \mathrm{m}$ beads was low (see 'Methods'). In some cases, this resulted in low numbers of $7 \mu \mathrm{m}$ beads being ingested, making the uncertainty of their counts higher than for the other bead sizes. As a check, we carried out parallel calculations of the forage ratio excluding $7 \mu \mathrm{m}$ beads. Thus, the total bead volume (i.e. $V G_{\text {Tol }}$ and $V S_{\text {Tol }}$ in Eq. 1) was the sum of 0.6, 1 and $3 \mu \mathrm{m}$ beads only. These new calculations did not change the conclusions for the 0.6 and $1 \mu \mathrm{m}$ beads, resulting in $<4 \%$ change in their mean retention efficiencies. In addition, Jacobs (1974) suggested that a modified forage ratio should be used in cases where 
Table 2. Oikopleura vanhoeffeni. Mean ( $\pm 95 \% \mathrm{CI}$ ) forage ratio and retention efficiency of all 4 bead sizes

\begin{tabular}{lccccc}
$\begin{array}{l}\text { Bead } \\
\text { diameter }(\mu \mathrm{m})\end{array}$ & $\mathrm{n}$ & Forage ratio & $\begin{array}{c}\text { Retention } \\
\text { efficiency } \%)\end{array}$ & $\begin{array}{c}\text { Lower } 95 \% \\
\mathrm{Cl}\end{array}$ & $\begin{array}{c}\text { Upper } 95 \% \\
\mathrm{Cl}\end{array}$ \\
\hline & & & & 36 & 52 \\
1 & 55 & $0.57 \pm 0.04$ & 44 & 50 & 66 \\
3 & 39 & $0.78 \pm 0.05$ & 58 & 82 & 94 \\
7 & 44 & $1.23 \pm 0.04$ & 98 & 88 & 94 \\
\hline
\end{tabular}

the proportions of various size particles are uneven. Although our experiments were designed to avoid this defect (see 'Methods'), as a check, we recalculated retention efficiencies using Jacob's Q-ratio in place of the forage ratio. These recalculations did not change the conclusions either, giving mean retention efficiencies of $0.6,1$ and $3 \mu \mathrm{m}$ beads of 45,66 and $92 \%$, respectively.

\section{DISCUSSION}

\section{Rejection of the food-concentrating filter model}

Although Oikopleura vanhoeffeni removed particles the size of free-living bacteria from suspension, it did so with much less than $100 \%$ efficiency, supporting our electron microscope measurements showing a relatively coarse pharyngeal filter (Deibel \& Powell 1987a), and reinforcing the view that the foodconcentrating filter, with a mean pore width of $0.22 \mu \mathrm{m}$ (Deibel et al. 1985), does not alone determine the size-

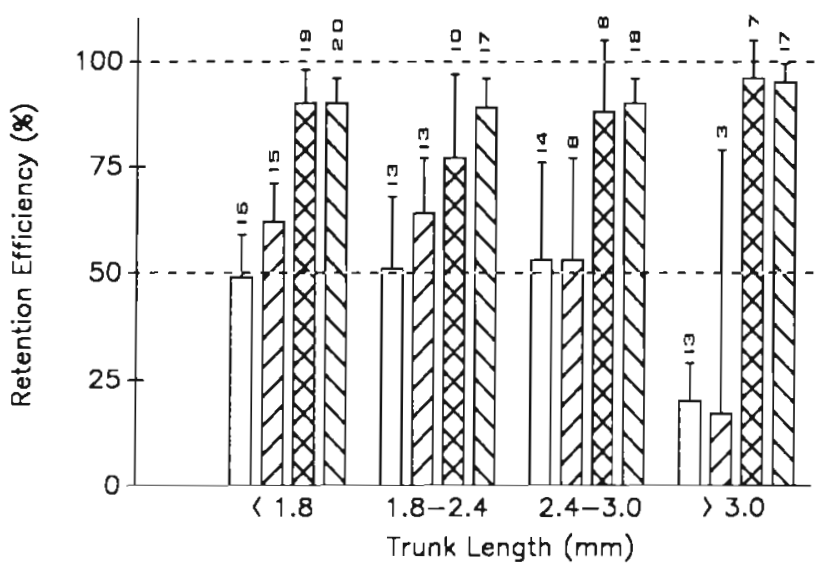

Fig. 2. Oikopleura vanhoeffeni. Frequency histogram of the mean retention efficiency of 0.6 (open bar), 1 ( $(7), 3$ ( 3 ) and $7 \mu \mathrm{m}$ beads $(0)$ by $O$. vanhoeffeni in 4 body-size classes Dotted lines indicate retention efficiencies of 50 and $100 \%$ Small numbers above error bars indicate $n$ for a given bead size and body-size class. All other labels and symbols are as in Fig. 1 frequency distribution of the ingested ration (Jørgensen 1984, Deibel \& Powell 1987a). Although it seems paradoxical that the pharyngeal filter of $O$. vanhoeffeni has larger pores than does the upstream foodconcentrating filter of its house, Bone et al. (1991) also found the pharyngeal filter of the salp Pegea confoederata to have large pores $(4 \times 0.7 \mu \mathrm{m})$. This introduces the possibility of a fundamental difference in pore size of the pharyngeal filters of pelagic tunicates vs benthic ascidian tunicates, which range from $0.5 \times$ 0.3 to $2.0 \times 0.5 \mu \mathrm{m}$ (Bone et al. 1991). Also, the foodconcentrating filter of $O$. vanhoeffeni concentrates the incoming particle suspension 100 to 1.000 times before it is pumped through the pharyngeal filter where particles are actually captured (Morris \& Deibel unpubl.). This concentration by tangential flow filtration may destabilize small suspended particles, leading to their coagulation into larger clumps within the house before final capture by the pharyngeal filter. The pharyngeal filter may be coarser to take advantage of this preaggregation effect.

\section{Overcapture by the pharyngeal filter}

The mean pore width of the pharyngeal filter of 4 large $O$. vanhoeffeni was $3.3 \pm 0.35 \mu \mathrm{m}( \pm 95 \% \mathrm{CI}$ ), as determined by transmission electron microscopy (TEM, Deibel \& Powell 1987a). Since this mean pore size should correspond to a capture efficiency of ca $50 \%$ (Harbison \& McAlister 1979), our empiricallydetermined retention efficiencies seem to indicate an overcapture of $3 \mu \mathrm{m}$ beads by 2 -fold (Fig. 2). This disagreement may be due to error or bias in the TEM measurements or, alternatively, to violation of the assumption that the pharyngeal filter works by sieving Preparation of specimens for TEM should have little effect on the dimensions of mucous filters if they are mounted on grids and air-dried, as we have done (Flood \& Fiala-Medioni 1981, Deibel \& Powell 1987a, Bone et al. 1991). More likely to influence predicted retention is the difficulty in measuring pores of the pharyngeal filter on TEM micrographs (Deibel \& Powell 1987a, Bone et al. 1991). Our assumption that 
those portions of the TEM micrographs having rectangular pores represented the least disturbed areas of the filter may have been false, and if so would result in an overestimate of mean pore size. There is also the possibility that the small beads formed clumps. Although there was no evidence of clumping of any of the beads in suspension in the experimental chambers, it is possible that they may have aggregated within the house before ingestion (Flood 1991). We have no direct measurement of particle state within the house

The most likely non-sieving mechanism for elevated retention of beads of this size is direct interception onto sticky, filter fibers (Rubenstein \& Koehl 1977). Recent theoretical arguments by Loudon \& Alstad (1990) demonstrate that when direct interception is important, experimentally-determined retention spectra give little accurate information about the pore size of the filter, with retention depending instead on complex interactions of flow velocity, particle size and concentration, and fiber diameter.

\section{More realistic model?}

It is possible that a sieving model is not appropriate at all, because the pharyngeal filter is a moving cone that compresses water and particles in its apex where it is wound into a mucous cord (Morris \& Deibel video obs.). In the real world, the concept of a characteristic pore size for the pharyngeal filter of pelagic tunicates may be meaningless. Empirical retention spectra may approach an asymptote at small particle size set by the degree of particle collection by direct interception. In addition, particles that pass through the pharyngeal filter are not lost from the house but flow into the tail chamber to be recycled through the food-concentrating filter (Deibel 1986, Flood 1991). Thus, it is theoretically possible that, given unlimited cycles through the house, a particle of infinitely small size eventually will be captured by direct interception onto a fiber of the pharyngeal filter

\section{Comparison to other tunicates}

The retention efficiencies we have measured agree with the only other studies of size selection by appendicularians of which we know (Paffenhöfer unpubl., A. W. Bedo, J. L. Acuña, D. Robins \& R. P. Harris unpubl.), which show that particles $>2 \mu \mathrm{m}$ diameter are retained with maximum efficiency by the smaller Oikopleura dioica. The mean retention efficiency of $0.6 \mu \mathrm{m}$ beads (44\%; Table 2 ) compares well with the ca $10 \%$ retention of colloidal Sepia ink $(0.13 \mu \mathrm{m}$ in diameter), that we measured in subsequent experiments (Flood et al.
1992). Thus, the retention spectrum of $O$. vanhoeffeni has the following characteristics: size of $100 \%$ retention is $>1$ but $<3 \mu \mathrm{m}$; size of $50 \%$ retention (retention index) is ca $0.6 \mu \mathrm{m}$; size of $10 \%$ retention is ca $0.15 \mu \mathrm{m}$.

The retention spectra of benthic ascidian tunicates are similar, with $1 \mu \mathrm{m}$ particles retained with 65 to $85 \%$ efficiency, and $100 \%$ retention of 2.5 to $3 \mu \mathrm{m}$ particles (Randlov \& Riisgård 1979, Jørgensen et al. 1984). Oikopleura vanhoeffeni retains small particles more efficiently than do the pelagic salps Cyclosalpa spp. and Salpa aspera, which have a size of $50 \%$ retention $>1.3$ but $<3.5 \mu \mathrm{m}$ (Harbison \& McAlister 1979. Kremer \& Madin 1992). The size of $100 \%$ retention of appendicularians and salps appears to be similar however, ranging from 1.8 to $4.6 \mu \mathrm{m}$ (Harbison \& McAlister 1979, Kremer \& Madin 1992, Bedo et al. unpubl.; Fig. 2). Thus, the slope of the retention spectrum of appendicularians must be less than that of salps, meaning that appendicularians retain submicrometer particles more efficiently than do salps.

It appears that the retention of sub-micrometer particles by salps (Harbison \& McAlister 1979, Kremer $\&$ Madin 1992) and appendicularians (Fig. 2) decreases with increasing body size. This inverse relationship also was found recently for Oikopleura longicauda. (Bedo pers comm.), and was predicted by the ultrastructural studies of Deibel \& Powell $(1987 \mathrm{a}, \mathrm{b})$. We conclude that as pelagic tunicates grow, they produce pharyngeal filters with ever larger pores.

This is the first study of the performance of the pharyngeal filter of an appendicularian, and the first attempt to compare ultrastructural predictions of particle retention with empirical measurements for any pelagic tunicate. Oikopleura vanhoeffeni, and perhaps all oikopleurid appendicularians (Paffenhöfer pers. comm., Bedo et al. unpubl.), consumes particles $>2 \mu \mathrm{m}$ in diameter with maximum efficiency, and therefore may mediate a shunt of the microbial loop from small Protozoa to metazoans, bypassing transfer through intermediate populations of small microbial predators, most notably ciliated Protozoa $100 \times$ smaller than $O$. vanhoeffeni and more than $1000 \times$ smaller than its house. Since theoretical calculations show that the number of predator-prey interactions in a food web is of greater importance to biomass production at terminal levels than is the efficiency of transfer at each step (Pomeroy \& Wiebe 1988), this reduction of mass transfer through intermediate populations of microbial predators of small size is of considerable bioenergetic significance. The small particle retention capabilities of tunicates are beyond the limits of even the juvenile stages of copepods (King et al. 1980, Støttrup \& Jensen 1990), and it is misleading to consider tunicates and copepods to have similar size-selection abilities (Sherr et al. 1986). The capability of tunicates to retain par- 
ticles the size of free-living bacteria also has methodological importance, because the popular dilution technique for determining predation on microbes does not include measurement of their consumption by metazoans. This may result in underestimation of bacterial and nanoflagellate mortality, and the premature conclusion that the microbial loop is primarily a sink of organic matter.

Acknowledgements. Many thanks to the Ocean Sciences Centre divers (Mr Gordon Chaisson, Divemaster) for helping with the collection of Oikopleura vanhoeffeni, to C. Bajdik, Memorial University, for discussions of statistics and presentation of data, and to $\mathrm{M}$. Riehl for computer graphics. A. Redden, R. Thompson, C. C. Morris, H. Vanderploeg, P. Flood, R. Harbison and P. Kremer kindly read and provided comments on earlier drafts. This work was supported by Operating and Equipment grants from the Natural Sciences and Engineering Research Council of Canada, and is Ocean Sciences Centre contribution no. 77

\section{LITERATURE CITED}

Alldredge, A. L., Madin, L. P. (1982). Pelagic tunicates: unique herbivores in the marine plankton. BioScience 32: 655-663

Bone, Q., Braconnot, J.-C., Ryan, K. P. (1991). On the pharyngeal feeding filter of the salp Pegea confoederata (Tunicata: Thaliacea). Acta. zool., Stockh. 72: 55-60

Caron, D. A., Madin, L. P., Cole, J. J. (1989). Composition and degradation of salp fecal pellets: implications for vertical flux in oceanic environments. J. mar. Res. 47: 829-850

Deibel, D. (1986). Feeding mechanism and house of the appendicularian Oikopleura vanhoeffeni. Mar. Biol. 93: $429-436$

Deibel, D., Dickson, M.-L., Powell, C. V. L. (1985). Ultrastructure of the mucous feeding filter of the house of the appendicularian Oikopleura vanhoeffeni. Mar. Ecol. Prog. Ser. 27: 79-86

Deibel, D., Powell, C. V. L. (1987a). Ultrastructure of the pharyngeal filter of the appendicularian Oikopleura vanhoeffeni: implications for particle size selection and fluid mechanics. Mar. Ecol. Prog. Ser. 35: 243-250

Deibel, D., Powell, C. V. L. (1987b). Comparison of the ultrastructure of the food concentrating filter of two appendicularians. Mar. Ecol. Prog. Ser. 39: 81-85

Ducklow, H. W. (1983). Production and fate of bacteria in the oceans. BioScience 33: 494-501

Flood, P. R. (1978). Filter characteristics of appendicularian food catching nets. Experientia 34: 173-175

Flood, P. R. (1991). Architecture of, and water circulation and flow rate in, the house of the planktonic tunicate Oikopleura labradoriensis. Mar. Biol. 111: 95-111

Flood, P. R., Fiala-Medioni, A. (1981). Ultrastructure and histochemistry of the food trapping mucous film in benthic filter-feeders (Ascidians). Acta zool., Stockh. 62: 53-65

This article was submitted to the editor
Flood, P. R., Deibel, D., Morris, C. C. (1992). Filtration of colloidal organic matter by planktonic tunicates. Nature, Lond (in press)

Harbison, G. R., McAlister, V. L. (1979). The filter-feeding rates and particle retention efficiencies of three species of Cyclosalpa (Tunicata, Thaliacea). Limnol. Oceanogr. 24: 875-- 892

Jacobs, J. (1974). Quantitative measurement of food selection: a modification of the forage ratio and Ivlev's electivity index. Oecologia 14: 413-417

Jorgensen, C. B. (1983). Fluid mechanical aspects of suspension feeding. Mar. Ecol. Prog. Ser. 11: 89-103

Jørgensen, C. B. (1984). Effect of grazing: metazoan suspension feeders. In: Hobbie, J. E., Williams, P. J LeB. (eds.) Heterotrophic activity in the sea. Plenum, New York, p. 445-464

Jørgensen, C. B., Kiørboe, T., Møhlenberg, F., Riisgård, H. U. (1984). Ciliary and mucous-net filter feeding, with special reference to fluid mechanical characteristics. Mar Ecol. Prog. Ser. 15: 283-292

Keats, D. W, Steele, D. H., South, G. R. (1987). Food of winter flounder Pseudopleuronectes americanus in a sea urchin dominated community in eastern Newfoundland. Mar. Ecol. 60: 13-22

King, K. R, Hollibaugh, J T., Azam, F. (1980). Predator-prey interactions between the larvacean Oikopleura dioica and bacterioplankton in enclosed water columns. Mar. Biol. 56 $49-57$

Kremer, P., Madin, L. P. (1992). Particle retention efficiency of salps. J Plankton Res. (in press)

Loudon, C., Alstad, D. N. (1990). Theoretical mechanics of particle capture: predictions for hydropsychid caddisfly distributional ecology. Am. Nat. 135: 360-381

Mullin, M. M. (1983). In situ measurement of filtering rates of the salp Thalia democratica, on phytoplankton and bacteria. J. Plankton Res. 5: 279-289

Pomeroy, L. R., Deibel, D. (1986). Temperature regulation of bacterial activity during the spring bloom in Newfoundland coastal waters. Science 223: 359-366

Pomeroy, L. R., Wiebe, W. J. (1988). Energetics of microbial food webs. Hydrobiologia 159: 7-18

Pomeroy, L. R., Wiebe, W. J., Deibel, D., Thompson, R. J., Rowe, G. T., Pakulski, J. D. (1991). Bacterial responses to temperature and substrate concentration during the Newfoundland spring bloom. Mar. Ecol. Prog. Ser 75: $143-159$

Randløv, A., Riisgård, H. U. (1979). Efficiency of particle retention and filtration rate in four species of ascidians. Mar. Ecol. Prog. Ser. 1:55-.59

Rubenstein, D. I., Koehl, M. A. R. (1977). The mechanisms of filter feeding: some theoretical considerations. Am. Nat. 111. 981-994

Sherr, E. B., Sherr, B. F., Paffenhöfer, G.-A. (1986). Phagotrophic protozoa as food for metazoans: a 'missing trophic link in marine pelagic food webs? Mar. Microb. Food Webs 1: 61-80

Støttrup, J. G., Jensen, J. (1990). Influence of algal diet on feeding and egg production of the calanoid copepod Acartia tonsa Dana. J. exp. mar. Biol. Ecol. 141: 87-105

Manuscript first received: April 24, 1991

Revised version accepted: February 11, 1992 